\title{
Quercetin inhibits a large panel of kinases implicated in cancer cell biology
}

\author{
RAINATOU BOLY ${ }^{1,3}$, THIERRY GRAS ${ }^{2}$, TOURIA LAMKAMI ${ }^{1}$, PIERRE GUISSOU ${ }^{3}$, \\ DIDIER SERTEYN $^{4,5}$, ROBERT KISS ${ }^{2}$ and JACQUES DUBOIS ${ }^{1}$
}

\author{
${ }^{1}$ Laboratoire de Chimie BioAnalytique, Toxicologie et Chimie Physique Appliquée and ${ }^{2}$ Laboratoire de Toxicologie, \\ Faculté de Pharmacie, Université Libre de Bruxelles (ULB), Brussels, Belgium; ${ }^{3}$ Laboratoire de Pharmacologie-Toxicologie \\ Appliquée, UFR/Sciences de la Santé, Université de Ouagadougou, Ouagadougou, Burkina Faso; ${ }^{4}$ Oxygen Centre, \\ Research and Development (CORD), Institute of Chemistry B6a and ${ }^{5}$ Department of Clinical Sciences, \\ Large Animal Surgery, Faculty of Veterinary, University of Liège, Liège, Belgium
}

Received September 14, 2010; Accepted October 29, 2010

DOI: $10.3892 /$ ijo.2010.890

\begin{abstract}
Flavonoids are polyphenolic secondary metabolites from plants that possess a common phenylbenzopyrone structure (C6-C3-C6). Depending upon variations in their heterocyclic C-ring, flavonoids are categorised into one of the following groups: flavones, flavonols, flavanones, flavanols, anthocyanidins, isoflavones or chalcones. Flavonols include, among others, the molecules quercetin, myricetin and kaempferol. The anticancer activity of flavonols was first attributed to their electron-donating ability, which comes from the presence of phenolic hydroxyl groups. However, an emerging view is that flavonoids, including quercetin, may also exert modulatory actions in cells by acting through the protein kinase and lipid kinase signalling pathways. Data from the current study showed that $2 \mu \mathrm{M}$ quercetin, a low concentration that represents less than $10 \%$ of its $\mathrm{IC}_{50}$ growthinhibitory concentration as calculated from the average of eight distinct cancer cell lines, decreased the activity of 16 kinases by more than $80 \%$, including ABL1, Aurora-A, -B, -C, CLK1, FLT3, JAK3, MET, NEK4, NEK9, PAK3, PIM1, RET, FGF-R2, PDGF-R $\alpha$ and -Rß. Many of these kinases are involved in the control of mitotic processes. Quantitative video microscopy analyses revealed that quercetin displayed strong anti-mitotic activity, leading to cell death. In conclusion, quercetin partly exerts its anticancer activity through the inhibition of the activity of a large set of kinases. Quercetin could be an interesting chemical scaffold from which to generate novel derivatives possessing various types of antikinase activities.
\end{abstract}

Correspondence to: Dr Robert Kiss, Laboratoire de Toxicologie, Faculté de Pharmacie, Université Libre de Bruxelles, Campus de la Plaine, Boulevard du Triomphe, CP205/1, 1050 Bruxelles, Belgium E-mail: rkiss@ulb.ac.be

Key words: agelanthus dodoneifolius, anticancer activity, in vitro, quercetin, kinases, apoptosis resistance

\section{Introduction}

Phytochemicals have become an important part of the available arsenal of anticancer drugs. Over $75 \%$ of non-biological anticancer drugs approved between 1981 and 2007 were either natural products or were developed based on such molecules $(1,2)$.

Agelanthus dodoneifolius Polhill \& Wiens Danser (Loranthaceae), previously named Tapinanthus dodoneifolius (African mistletoe), is a common plant that both parasitizes plants such as Mimosaceae and Sapotaceae and displays a wide range of medicinal properties $(3,4)$. Phytochemical screenings of the plant have revealed the presence of tannins, anthracenosides, anthraquinones, flavonoids, anthocyanosides, sterols, triterpenes and saponosides $(3,4)$. In this study, we focused primarily on the flavonoid component of Agelanthus dodoneifolius and more closely on quercetin.

Flavonoids are polyphenolic plant secondary metabolites that possess a common phenylbenzopyrone structure (C6C3-C6). According to variations in their heterocyclic C-ring, flavonoids may be categorised as flavones, flavonols, flavanones, flavanols, anthocyanidins, isoflavones or chalcones $(2,5)$. More than 4,000 types of flavonoids have already been identified (6).

Specific examples of flavonols include quercetin, myricetin and kaempferol $(2,5)$. The anticancer activity of the flavonols was first attributed to their ability to donate electrons from their phenolic hydroxyl groups $(2,6)$. However, although there has been a major focus on the antioxidant properties of flavonoids (7), there is an emerging view that the flavonoids, including quercetin, do not act only as conventional hydrogendonating antioxidants but may also exert modulatory actions on cells through both protein kinase and lipid kinase signalling pathways $(8,9)$. In addition, flavonoids have been reported to act on phosphoinositide (PI) -3-kinase, Akt/protein kinase B (PKB), tyrosine kinases, protein kinase $\mathrm{C}$ (PKC) and mitogenactivated protein (MAP) kinase signalling cascades $(8,9)$. As emphasised by Williams et al (8), inhibitory or stimulatory actions at these pathways are likely to profoundly affect cellular functions such as cell proliferation, cell death, and/or 
cell migration by altering the phosphorylation state of target molecules and modulating gene expression.

Flavonoids, including quercetin, may also influence the activity of epigenetic-modifying enzymes in cancer cells (10) and/or induce apoptosis via the mitochondrial pathway (7). Quercetin aglycone has been shown to modulate several signal transduction cascades involving the MEK/ERK and NRF2/KEAP1 pathways, which are associated with the processes of inflammation and carcinogenesis (6). Quercetin also induces ubiquitination and down-regulation of HER-2/ NEU, a transmembrane tyrosine kinase that acts as a coreceptor together with other EGFR (epithelial growth factor receptor) family members (11). Jagtap et al (7) provided a list of about 20 molecular targets of quercetin.

Although several hundred studies have looked at the relationship between quercetin and kinases, to the best of our knowledge, this study is the first to characterize the global antikinase profile of quercetin against a panel of 300 kinases. We have paid particular attention to quercetin because it is one of the components that we identified from Agelanthus dodoneifolius as a contributor to the anticancer activity of this plant.

\section{Materials and methods}

Plant material. The leaves of Agelanthus dodoneifolius (Loranthaceae) were collected during the period from October to November of 2005. The plant was found on a sheanut tree [Vitellaria paradoxa CF Gaertn (Sapotaceae)] in the region of Ouagadougou (Burkina Faso). The plant identity was determined by Professor I.J. Boussim from the Plant Ecology and Biology Laboratory at Ouagadougou University. A sample specimen was deposited and bears voucher number 01 and 02 .

Extraction of flavonoids. The dried and powdered leaves of Agelanthus dodoneifolius (60 g) were treated with boiling methanol (ChemLab, Zedelgem, Belgium) at room temperature. The extract was concentrated to dryness under reduced pressure. The residue was resuspended in boiling water $(100 \mathrm{ml})$ and successively exhausted with petroleum ether (3x100 ml), diethyl ether (3x100 ml; VWR, Leuven, Belgium), ethyl acetate $(3 \times 100 \mathrm{ml}$; ChemLab) and n-butanol (3x100 ml; VWR). Each fraction was dried under reduced pressure and stored in a desiccator prior to the biological assays. The petroleum ether fraction was not used because it contained virtually no flavonoids, as shown by thin layer chromatography (TLC; VWR, Leuven, Belgium).

For the aqueous extracts, the shade dried leaves of Agelanthus dodoneifolius were powdered before extraction. A decoction was made by bringing $100 \mathrm{~g}$ of powdered leaves to boil in 11 of distilled water for $15 \mathrm{~min}$. Then, the extract was filtered, frozen and freeze-dried (Christ, Alpha 1-2 LD; Osterode, Germany).

Determining $I C_{50}$ in vitro growth inhibition concentrations. We used one mouse and seven human cancer cell lines that were obtained from the European Collection of Cell Culture (ECACC, Salisbury, UK), the American Type Culture Collection (ATCC, Manassas, VA, USA) and the Deutsche Sammlung von Mikroorganismen und Zellkulturen, (DSMZ, Braunschweig, Germany). The human cancer cell lines included the non-small cell lung cancer (NSCLC) line A549 (DSMZ code ACC107), the melanoma line SKMEL-28 (ATCC code HTB-72), the glioblastoma lines U373 (ECACC code 89081403) and T98G (ATCC code CRL1690), the colon cancer line LoVo (DSMZ code ACC350), the breast cancer line MCF-7 (DSMZ code ACC115) and the prostate cancer line PC-3 (DSMZ code ACC465), and the mouse cancer cell line used was the melanoma line B16F10 (ATCC code CRL6475). The cancer cell lines under study were cultured in RPMI medium (Invitrogen, Merelbeke, Belgium) supplemented with $10 \%$ heat-inactivated foetal calf serum, $4 \mathrm{mM}$ glutamine, $100 \mu \mathrm{g} / \mathrm{ml}$ gentamycin and penicillin-streptomycin (200 U/ml and $200 \mu \mathrm{g} / \mathrm{ml}$, respectively; Invitrogen).

The overall growth levels of the human cancer cell lines were determined using the colorimetric MTT [3-(4,5dimethylthiazol-2yl)]-diphenyltetrazolium bromide, Sigma, Belgium) assay (12-17). Briefly, cell lines were incubated for $24 \mathrm{~h}$ in 96-microwell plates at concentrations of 10,00040,000 cells $/ \mathrm{ml}$, depending on the cell type, to ensure adequate plating prior to making cell growth determinations. The assessment of cell growth using the MTT colorimetric assay was based on the capability of living cells to reduce the yellow product MTT [3-(4,5)-dimethylthiazol-2-yl-2,5diphenyltetrazolium bromide] to a blue product, formazan, by a reduction reaction that occurs in the mitochondria. The number of living cells after $72 \mathrm{~h}$ of culture in the presence (or absence for the negative control) of the various compounds was directly proportional to the intensity of the blue colour, which was measured quantitatively by spectrophotometry using a Bio-Rad Model 680XR (Bio-Rad, Nazareth, Belgium) at the 570-nm wavelength (with a reference wavelength of $630 \mathrm{~nm}$ ). Each experimental condition was run six times (12-17). Quercetin was obtained from Sigma (Bornem, Belgium), and quercetin-3-O-glucuronide (miquelianin) and quercetin-3-Ogalactoside (hyperoside) were obtained from Carbosynth (Compton, Berkshire, England).

Computer-assisted phase-contrast microscopy (quantitative video-microscopy). The direct visualisation of the effects of quercetin on human T98G glioblastoma cells was carried out by computer-assisted phase contrast microscopy (quantitative video-microscopy), as detailed elsewhere $(13,18-21)$. T98G glioblastoma cells were monitored for $72 \mathrm{~h}$ in the absence (control) or presence of $30 \mu \mathrm{M}$ quercetin, which is the $\mathrm{IC}_{50}$ in vitro growth-inhibitory concentration as calculated by the MTT colorimetric assay (Fig. 1Ab). Movies were created from the time-lapse image sequences, which enabled a detailed screen for cell viability to determine whether the compound induced cytostatic or cytotoxic effects $(13,18-21)$. Each experimental condition was performed in triplicate.

Kinase activity determination. We originally treated ProQinase (Freiburg, Germany) with quercetin as a stock solution in $100 \%$ DMSO, from which the aliquots were further diluted with water in 96-well microtiter plates directly before use. For each kinase assay, $5 \mu \mathrm{l}$ from either a $2.10^{6} \mathrm{M} / 10 \%$ DMSO or a $3.10^{5} \mathrm{M} / 10 \%$ DMSO compound solution was transferred to the assay plates. The final volume in each well of the assay was $50 \mu 1$. The final concentrations for quercetin were either 2 or $30 \mu \mathrm{M}$. 
Table I. Quantitative determination by UPLC-MS/MS analyses on the proportion of various phenolic compounds in various fractions from Agelanthus dodoneifolius and the determination of $\mathrm{IC}_{50}$ in vitro growth-inhibitory concentrations of these fractions in three human cancer cell lines.

\begin{tabular}{|c|c|c|c|c|c|c|c|}
\hline \multirow[t]{2}{*}{ Fractions } & \multicolumn{4}{|c|}{$\%$ of phenolic compounds } & \multicolumn{3}{|c|}{$\begin{array}{l}\mathrm{IC}_{50} \text { in vitro growth-inhibitory } \\
\text { concentration }(\mu \mathrm{g} / \mathrm{ml})\end{array}$} \\
\hline & Gallic acid & Catechin & Rutin & Quercetin & A549 & U373 & LoVo \\
\hline Aqueous decoction & 0.4 & 0.7 & 0.2 & Not detected & $>100(66 \%)$ & 75 & $>100(77 \%)$ \\
\hline Diethyl ether & 2.1 & 10.5 & $<0.1$ & 0.3 & 47 & 98 & 49 \\
\hline Ethyl acetate & 1.0 & 5.7 & 0.3 & 0.2 & $>100(56 \%)$ & 95 & 50 \\
\hline Butanolic & 0.1 & 0.1 & 0.8 & Not detected & $>100(92 \%)$ & $>100(75 \%)$ & $>100(56 \%)$ \\
\hline
\end{tabular}

The three human cancer cell lines included the A549 non-small cell lung cancer (NSCLC), the U373 glioblastoma (GBM) and the LoVo colon cancer models. The percentages under parentheses when the $\mathrm{IC}_{50}$ values are $>100 \mu \mathrm{g} / \mathrm{ml}$ represent the percentages of surviving cancer cells at $100 \mu \mathrm{g} / \mathrm{ml}$ after 3 days of cell culture with the extracts. UPLC-MS/MS is defined as Ultra Performance Liquid Chromatography coupled to tandem mass spectrometry.

A radiometric protein kinase assay ${ }^{33}$ PanQinase ${ }^{\circledR}$ Activity assay) was used for measuring the kinase activity of the 256 protein kinases under study as detailed previously (15). All kinase assays were performed in 96-well FlashPlates ${ }^{\mathrm{TM}}$ (Perkin Elmer, Boston, MA, USA) in a $50 \mu 1$ reaction volume. The reaction cocktail was assembled in the following order: i) $10 \mu \mathrm{l}$ of the non-radioactive ATP solution (in $\mathrm{H}_{2} \mathrm{O}$ ), ii) $25 \mu \mathrm{l}$ of the assay buffer $\left[\gamma^{3}{ }^{33} \mathrm{P}\right]$-ATP mixture, iii) $5 \mu \mathrm{l}$ of the test sample in $10 \%$ DMSO and iv) $10 \mu \mathrm{l}$ of the enzyme/substrate mixture. The assay mixture for all enzymes contained $60 \mathrm{mM}$ HEPES-NaOH, pH 7.5, $3 \mathrm{mM} \mathrm{MgCl}_{2}, 3 \mathrm{mM} \mathrm{CaCl} 2,3 \mu \mathrm{M}$ Na-orthovanadate, $1.2 \mathrm{mM}$ DTT, $50 \mu \mathrm{g} / \mathrm{ml} \mathrm{PEG}_{20000}, 1 \mu \mathrm{M}$ ATP/ $\left[\gamma-{ }^{33} \mathrm{P}\right]-\mathrm{ATP}$ (approximately $6 \times 10^{5} \mathrm{cpm}$ per well), protein kinase (variable amounts; 15) and substrate (variable amounts; 15).

All PKC assays except for the PKC-mu and the PKC-nu assays also contained $1 \mathrm{mM} \mathrm{CaCl}{ }_{2}, 4 \mathrm{mM}$ EDTA, $5 \mu \mathrm{g} / \mathrm{ml}$ phosphatidylserine and $1 \mu \mathrm{g} / \mathrm{ml} \mathrm{1.2-dioleyl-glycerol.} \mathrm{The}$ MYLK2, CAMK1d, CAMK2a, CAMK2b, CAMK2d, CAMK4, CAMKk2, DAPK2 and EEF2K assays also contained $1 \mu \mathrm{g} / \mathrm{ml}$ calmodulin and $0.5 \mathrm{mM} \mathrm{CaCl}_{2}$. The PRKG1 and PRKG2 assays also contained $1 \mu \mathrm{M}$ cGMP (15).

The recombinant human protein kinases were expressed in either Sf9 insect cells or in E. coli as either GST-fusion proteins or His-tagged proteins (ProQinase). The kinases were purified by affinity chromatography using either GSHagarose or Ni-NTH-agarose (ProQinase). The purity of each kinase was determined by SDS-PAGE/silver staining, and the identity of each kinase was verified by mass spectroscopy (ProQinase).

The reaction cocktails were incubated at $30^{\circ} \mathrm{C}$ for $60 \mathrm{~min}$. The reaction was stopped with $50 \mu \mathrm{l}$ of $2 \%(\mathrm{v} / \mathrm{v}) \mathrm{H}_{3} \mathrm{PO}_{4}$; plates were then aspirated and washed 2 times with $200 \mu 1$ of $0.9 \%$ $(\mathrm{w} / \mathrm{v}) \mathrm{NaCl}$. Incorporation of ${ }^{33} \mathrm{P}_{\mathrm{i}}$ was determined with a microplate scintillation counter (Wallac Microbeta, Perkin Elmer, MA). All assays were performed with a Beckman Coulter/Sagian robotic system (Krefeld, Germany).

The median value of the counts in column $1(n=8)$ of each assay plate was defined as the 'low control'. This value reflected the non-specific binding of the radioactivity to the plate in the absence of a protein kinase, but in the presence of the substrate. The median value of the counts in column 2 of each assay plate $(n=8)$ was taken as the 'high control', at which concentration there was full activity in the absence of any inhibitor. The difference between high and low control counts was taken as $100 \%$ activity.

As part of the data evaluation, the low control value from a particular plate was subtracted from the high control value as well as from all 'compound values' of the corresponding plate. The residual activity (in \%) for each well of a particular plate was calculated by using the following formula:

Res. Activity $(\%)=100 \times[(\mathrm{cpm}$ of compound - low control $) /$ (high control - low control)]

The $\mathrm{Z}$-factor for the low and high controls of each assay plate was used by ProQinase as a parameter for assay quality. The ProQinase criterion for repetition of an assay plate was a Z'-factor below 0.4 (15).

\section{Results}

Agelanthus dodoneifolius organic extracts contain quercetin and display in vitro anticancer activity. The data in Table I show that both the diethyl ether and ethyl acetate extracts from Agelanthus dodoneifolius contained quercetin and displayed in vitro anticancer activity, meaning that the $\mathrm{IC}_{50}$ growth-inhibitory concentrations were less than $100 \mu \mathrm{g} / \mathrm{ml}$. In contrast, the two extracts that did not contain detectable amounts of quercetin, both the aqueous decoction and the butanolic extract, displayed no or only weak growth-inhibitory activity (Table I). Therefore, we decided to pursue our investigations by analysing the quercetin antikinase profile as detailed below.

Quercetin displays in vitro anticancer activity. The effect of quercetin on cellular proliferation (Fig. 1Aa) was assayed in seven human and one mouse (B16F10) cancer cell lines, and its $\mathrm{IC}_{50}$ in vitro growth-inhibitory concentrations were very 
<smiles>O=c1c(O)c(-c2ccc(O)c(O)c2)oc2cc(O)cc(O)c12</smiles>

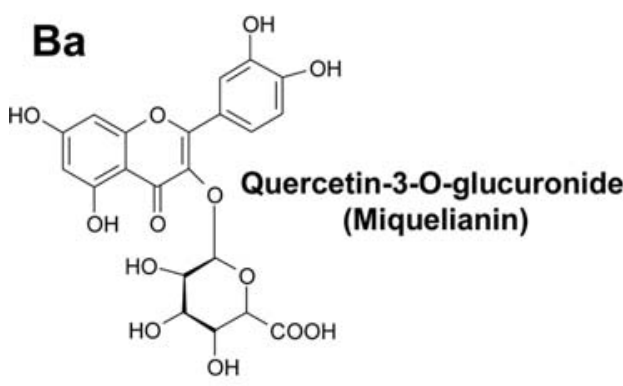

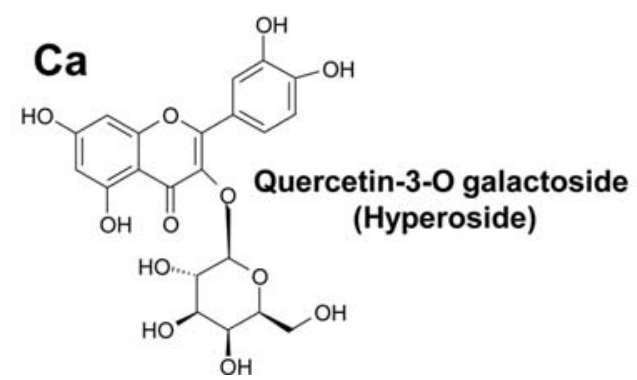

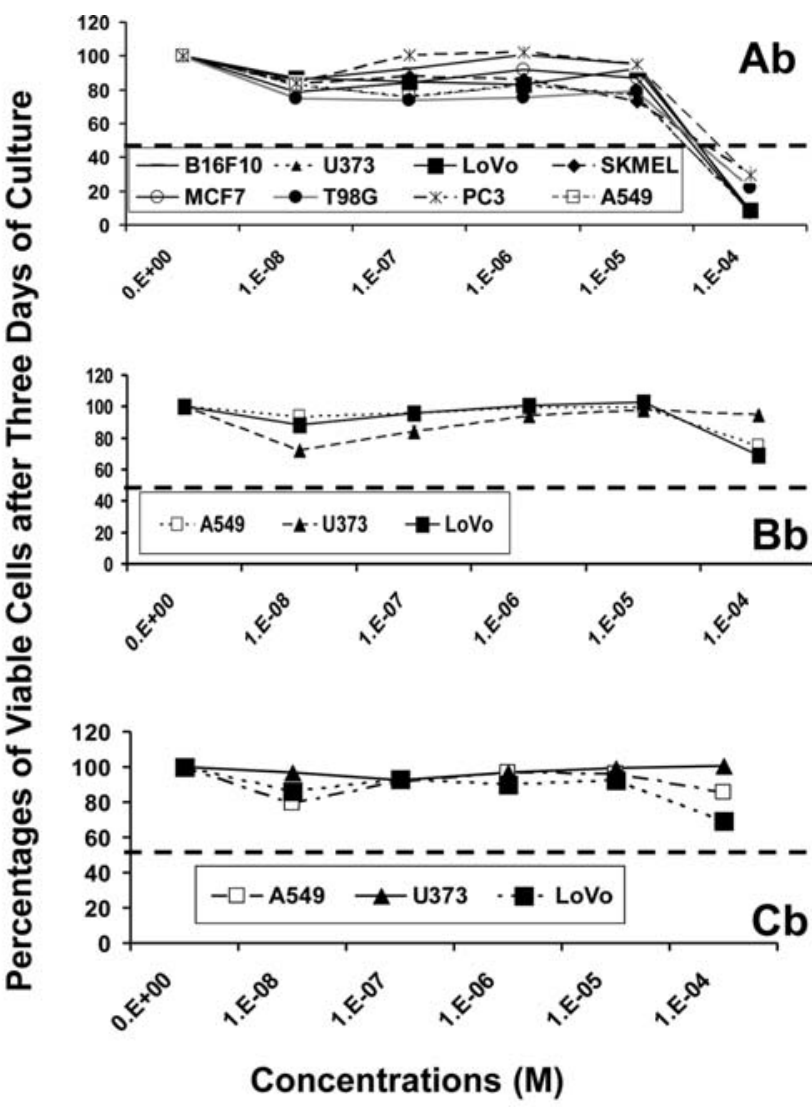

Figure 1. Characterisation of the in vitro growth-inhibitory effects induced by quercetin, quercetin-3-O-glucuronide (miquelianin) and quercetin-3-Ogalactoside (hyperoside) in seven human (U373, T98G, LoVo, SKMEL-28, MCF-7, PC-3 and A549) and one mouse (B16F10) cancer cell lines.

similar among these eight cancer cell lines: $26 \pm 5 \mu \mathrm{M}$ in $\mathrm{B} 16 \mathrm{~F} 10 ; 31 \pm 1 \mu \mathrm{M}$ in $\mathrm{U} 373 ; 32 \pm 1 \mu \mathrm{M}$ in MCF-7; $33 \pm 2 \mu \mathrm{M}$ in $\mathrm{T} 98 \mathrm{G} ; 34 \pm 2 \mu \mathrm{M}$ in $\mathrm{A} 549 ; 33 \pm 1 \mu \mathrm{M}$ in LoVo; $38 \pm 2 \mu \mathrm{M}$ in SKMEL-28; and 44 $\pm 1 \mu \mathrm{M}$ in PC-3 cancer cells (Fig. 1Ab).

In contrast, the two quercetin-related glycosylated derivatives quercetin-3-O-glucuronide (miquelianin; Fig. 1Ba) and quercetin-3-O-galactoside (hyperoside; Fig. 1Ca) displayed no in vitro anticancer activity (Fig. 1), as evidenced by having $\mathrm{IC}_{50}$ growth-inhibitory concentrations of more than $100 \mu \mathrm{M}$ (Fig. $1 \mathrm{Bb}$ and $\mathrm{Cb}$ ).

Quercetin is a cytostatic rather than a cytotoxic compound. Quantitative video-microscopy analyses found that the growthinhibitory activity of quercetin as determined by the MTT colorimetric assay (Fig. 1Ab) acted through cytostatic rather than cytotoxic effects (Fig. 2). Indeed, human T98G glioblastoma cells given quercetin at the $\mathrm{IC}_{50}$ in vitro growthinhibitory concentration of $30 \mu \mathrm{M}$ displayed a markedly decreased rate of proliferation. It appears that quercetin blocked T98G cells in the mitotic phase and that this blockade led to cell death (Fig. 2). The cytostatic effects of quercetin treatment on mitosis could be related to the inhibitory effect of quercetin on the NIMA-related kinases (NEK), Aurora kinases and PAK kinases, as discussed below.

Quercetin is a multi-antikinase compound. Quercetin was found to decrease the activity of $\sim 100$ kinases by greater than $95 \%$ (Fig. 3) at $30 \mu \mathrm{M}$, very close to the mean $\mathrm{IC}_{50}$ in vitro growth-inhibitory concentration of $34 \pm 2 \mu \mathrm{M}$ that was calculated for the eight cancer cell lines studied (Fig. 1Ab). We then investigated the multi-antikinase effects of a much lower concentration for quercetin, i.e., $2 \mu \mathrm{M}$, which represents about $7 \%$ of its mean $\mathrm{IC}_{50}$ in vitro growth-inhibitory concentration (see above). At this low concentration, quercetin still decreased the activity of $\sim 15$ kinases by greater than $95 \%$ and decreased the activity of a remaining set of $\sim 50$ kinases by between 80 and $95 \%$ (Fig. 3). In Fig. 4, we report the kinases for which $2 \mu \mathrm{M}$ quercetin decreased their residual activity by at least $90 \%$. We believe it is reasonable to consider the kinases for which the activity was reduced by at least $90 \%$ at a concentration of $2 \mu \mathrm{M}$, which is only $7 \%$ of the $\mathrm{IC}_{50}$ growth-inhibitory concentration found for the various cancer cell lines tested, to probably be specific targets for quercetin. The kinases with barely detectable activity after treatment with $2 \mu \mathrm{M}$ quercetin were Cdc2-like kinase-1 (CLK1), insulin receptors (INSR-R) and muscle specific kinase (MUSK; Fig. 4).

Quercetin displays specific inhibitory effects in various groups of kinases. We have split the group of $\sim 30$ kinases illustrated in Fig. 4 into their respective subgroups of kinases as illustrated in Fig. 5A-L. For example, Fig. 4 shows that $2 \mu \mathrm{M}$ quercetin reduced the activity of ABL1, which has various mutated forms, by $91 \%$. Fig. 5A illustrates the effect of $2 \mu \mathrm{M}$ quercetin on ABL1 and its mutated forms. Fig. 4 shows that $2 \mu \mathrm{M}$ quercetin reduced the activity of Aurora B, which belongs to a sub-group of three kinases, by $92 \%$. Fig. 5B 


\section{Human T98G Glioblastoma Cells}
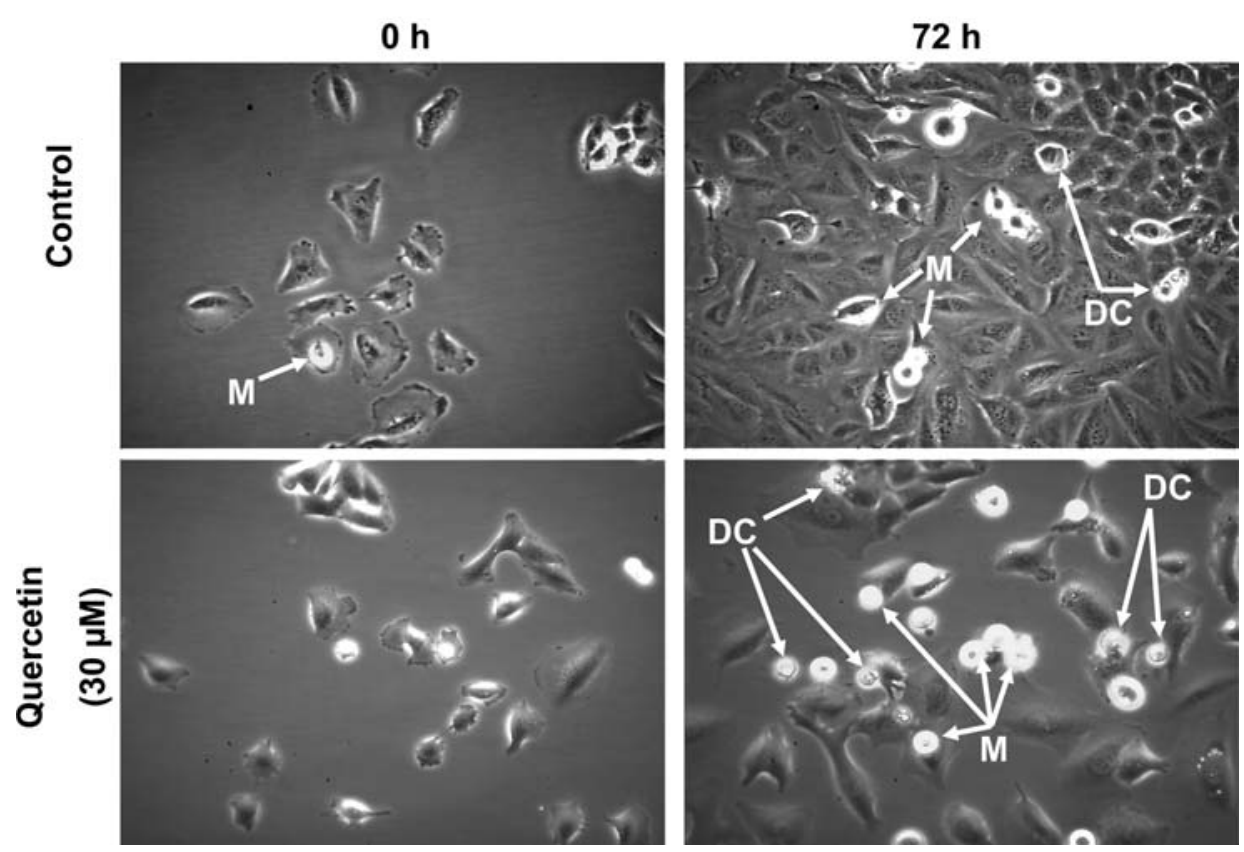

Figure 2. Morphological illustrations of the anticancer effects observed after $72 \mathrm{~h}$ of culturing human T98G glioblastoma cells with $30 \mu \mathrm{M}$ quercetin. The cells that are entering mitosis (M) are round, refringent and display a dark spot in their centrum, whereas dying cells (DC) are also refringent but display heterogeneous morphological patterns.

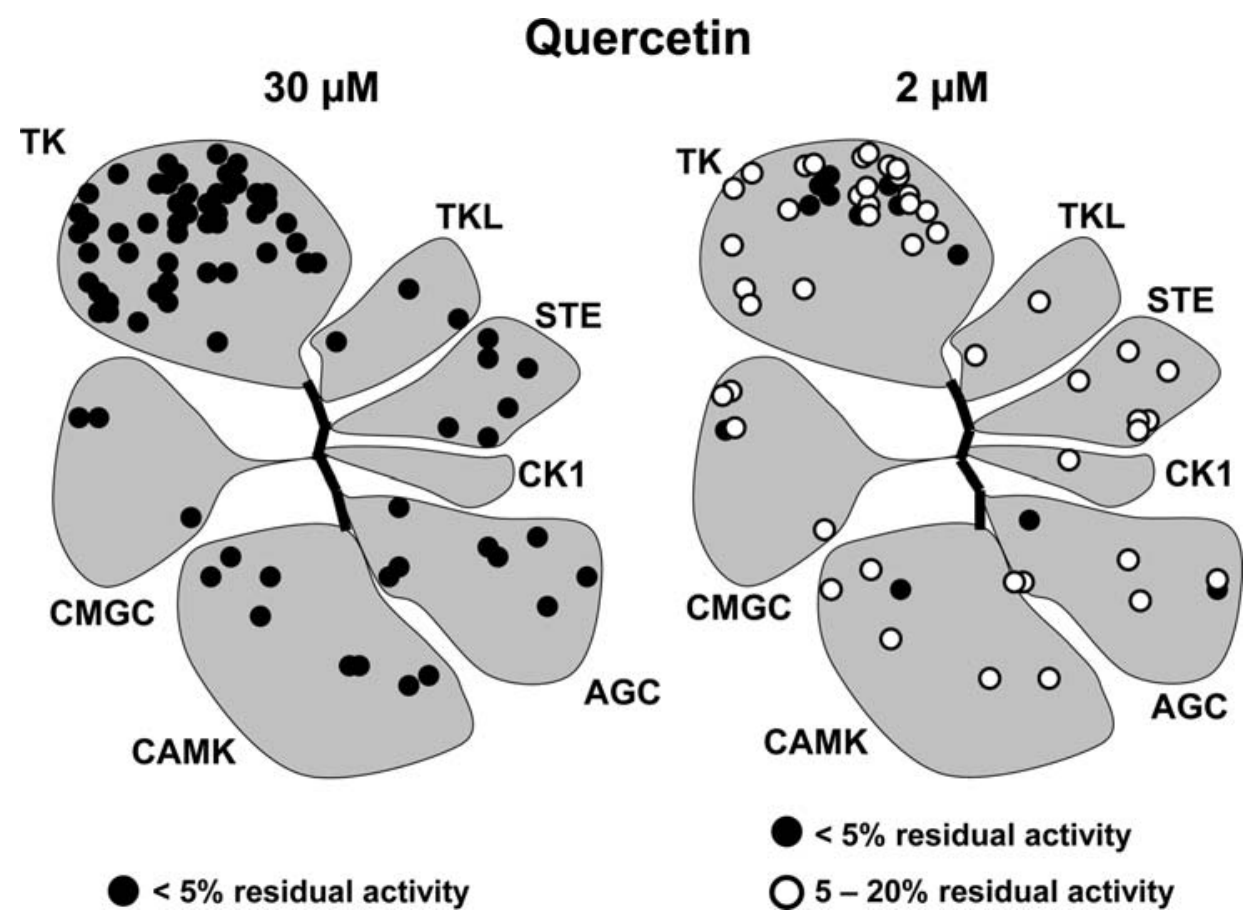

Figure 3. Characterisation of quercetin-induced anti-kinase activity. A schematic illustration of the kinases in the human dendrogram-related kinome that were targeted at two concentrations with analyses of $<5 \%(30 \mu \mathrm{M})$ versus $<5 \%$ and $5-20 \%(2 \mu \mathrm{M})$ of kinase residual activity. The various classes of kinases included tyrosine kinases (TK), tyrosine kinase-like kinases (TKL), serine/threonine protein kinases (STE), casein kinases (CK1), cAMP-dependent protein kinases (AGC), calcium/calmodulin protein kinase II kinases (CAMK) and the CMGC sub-class, which includes cyclin-dependent kinase (CDK), mitogenactivated protein kinase (MAPK), glycogen synthase kinase (GSK), and CDK-like groups of kinases.

shows the result of $2 \mu \mathrm{M}$ quercetin treatment on the Aurora A, $\mathrm{B}$ and $\mathrm{C}$ kinases, and so on for the remaining kinases that are illustrated in Fig. 4.
Fig. 5A shows that quercetin displays similar inhibitory activity on the wild-type (wt) and on various mutated forms of the ABL1 kinase. As recently emphasised by Agrawal et al 


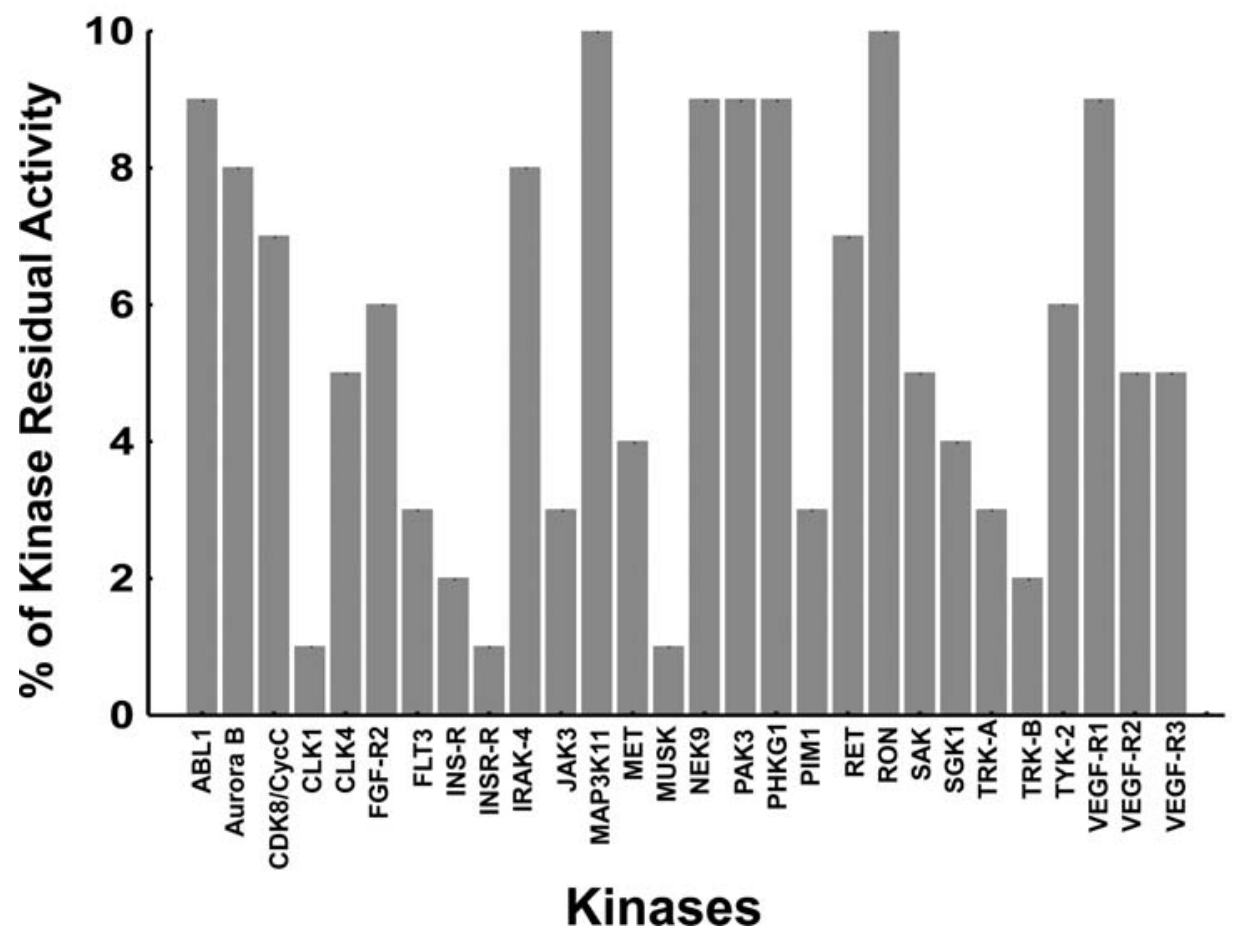

Figure 4. Identification of the kinases whose residual activity dropped below $10 \%$ (control $=100 \%$ ) when treated with $2 \mu \mathrm{M}$ quercetin.

(22), the drug imatinib mesylate, a Bcr-Abl1 tyrosine kinase inhibitor, has revolutionised treatment for chronic myeloid leukaemia (CML). By directly targeting the Bcr-Abl kinase, imatinib treatment can lead to durable cytogenetic remission and, in turn, improve survival. However, many patients with CML develop resistance, fail to respond, or become intolerant to imatinib due to side effects (22). This response has spurred interest in developing second-generation TKIs to overcome the mechanisms of resistance that lead to treatment failure, specifically Bcr-Abl1 kinase domain mutations (22). Unfortunately, many patients fail subsequent treatment with these agents because they can develop highly resistant mutations such as T315I (22). Fig. 5A clearly indicates that quercetin inhibited both the wild-type and the mutated T315I forms of ABL1.

Although not as potent as some of the specifically-designed Aurora kinase inhibitors $(23,24)$, quercetin was found to significantly inhibit the activity of the three Aurora kinases at $2 \mu \mathrm{M}$ (Fig. 5B), which is only $7 \%$ of the mean $\mathrm{IC}_{50}$ in vitro growth-inhibitory concentration (see above). Aurora kinases $\mathrm{A}$ and $\mathrm{B}$ are essential components of the mitotic pathway, ensuring proper chromosome assembly, formation of the mitotic spindle, and cytokinesis $(23,24)$. The role of Aurora C is less clear $(23,24)$. Overexpression of Aurora A and B has been observed in several tumour types and has been linked with a poor prognosis of cancer patients $(23,24)$. The combination of Aurora inhibitors with other chemotherapeutic agents may open new opportunities in cancer chemotherapy (24).

Quercetin markedly inhibited the activity of both the CLK1 and CLK4 kinases at $2 \mu \mathrm{M}$ but inhibited to a much lower extent the activities of the CLK2 and CLK3 kinases (Fig. 5C). Therefore, quercetin seems to represent a rather specific inhibitor of CLK1 within the CLK subgroup of kinases. The
CLK kinases are implicated in the circadian rhythm/biological clock systems (25).

The fms-like receptor tyrosine kinase-3 (FLT3) is important for the normal development of hematopoietic stem cells and cells of the immune system, and it is frequently mutated in patients with acute myeloid leukaemia (AML; 26). Quercetin had similar inhibitory activity on the wild-type form of FLT3 and two of its mutated forms (Fig. 5D).

Flavonoids are already known to inhibit Janus kinase 1 (JAK1) activity (27). Fig. 5E shows that quercetin markedly inhibited JAK3 activity, had intermediate inhibitory activity on JAK2 kinase and had little or no effect on the activity of JAK 1 kinase. JAK3 is a non-receptor tyrosine kinase, predominantly expressed in hematopoietic cells, that has been implicated in the signal transduction of the common $\gamma$ chain subfamily of cytokine receptors (28). JAK3-inactivating mutations result in immunodeficiency syndromes (SCID) in both humans and mice (28). Abnormal activation of JAK3 due to activating mutations is also found in human haematological malignancies, including acute megakaryoblastic leukaemia (AMKL) and cutaneous T cell lymphoma (CTCL) (28).

Fig. $5 \mathrm{~F}$ shows that $2 \mu \mathrm{M}$ quercetin greatly decreased the activity of the MET kinase and its mutated forms. MET is a tyrosine kinase receptor that, upon binding to its natural ligand, the hepatocyte growth factor (HGF), is phosphorylated and subsequently activates different signalling pathways involved in proliferation, motility, migration and invasion (29). Canadas et al (29) reported that MET is aberrantly activated in human cancer by mutation, amplification or protein overexpression. MET expression and activation have been associated with prognosis and predicted response to MET inhibitors in preclinical models for a number of tumour types (29). 

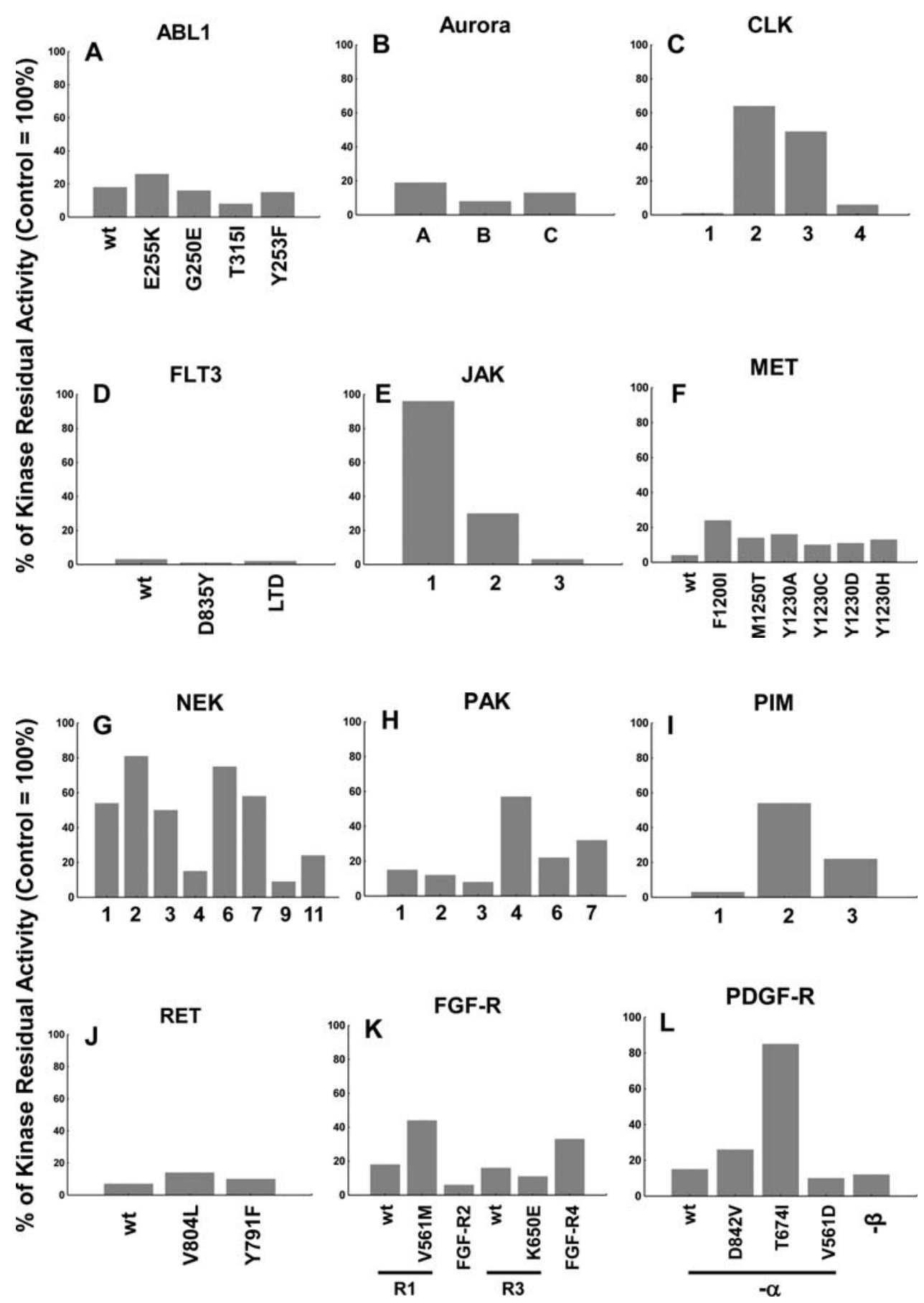

Figure 5. Identification of the kinases that may have been specifically targeted by $2 \mu \mathrm{M}$ quercetin listed as specific groups of kinases and their mutated forms.

The NIMA-related kinases represent a family of serine/ threonine kinases implicated in cell cycle control (30). Mammals contain a large family of eleven NIMA-related kinases, named NEK1 through NEK11, and of these, there is now substantial evidence that NEK2, NEK6, NEK7 and NEK9 also regulate mitotic events (30). As detailed in the discussion, NEK kinases are not yet well studied as potential targets in cancer therapy. Fig. 5G shows that quercetin significantly targeted NEK4 and NEK9 as compared to the remaining 8 NEK kinases under study.

The PAKs (p21-activated kinases) are a family of effector proteins for Rho-family GTPases Rho, Rac and Cdc42 that regulate physiological processes including cell migration, survival, mitosis, transcription and translation, and actin cytoskeleton dynamics $(32,33)$. There are six mammalian PAKs that can be divided into two groups: group I PAKs (PAK1-3) and group II PAKs (PAK4-6; 33). Group I PAKs are activated by extracellular signals through GTPase-dependent and GTPase-independent mechanisms, whereas group II PAKs are constitutively active (32). Fig. $5 \mathrm{H}$ shows that $2 \mu \mathrm{M}$ quercetin lowered the activity by a greater degree in group I than in group II PAKs.

Quercetin at a concentration of $2 \mu \mathrm{M}$ almost completely obliterated the activity of PIM1 kinase and it also greatly 
reduced the activity of the PIM2 and PIM3 kinases (Fig. 5I). The PIM1 kinase is an oncogene implicated in early transformation and tumour progression in haematopoietic malignancies and prostate carcinomas; it is also associated with the more aggressive subgroups of lymphoma (34). PIM kinases are induced by the JAK/STAT-dependent pathway (35). Interestingly, low-dose quercetin also markedly inhibited JAK2 and JAK3 (Fig. 5E) in addition to PIM1 (Fig. 5I).

The data in Fig. 5J show that $2 \mu \mathrm{M}$ quercetin inhibited the RET kinase and two of its mutated forms to a high degree. The RET kinase has been implicated in the development of multiple endocrine neoplasia (MEN) syndromes and familial medullary thyroid carcinoma (36).

Quercetin $(2 \mu \mathrm{M})$ greatly inhibited FGF-R activity, having similar effects on the wild-type and mutated forms of FGF-R with maximal quercetin-induced inhibitory activity on the kinase FGF-R2 (Fig. 5K). The FGF-Rs play important roles as signalling molecules governing angiogenesis, an attractive target for drug therapy due to its key role in tumour growth (37). FGFs (fibroblast growth factors) and their receptors also control a wide range of biological functions regulating cellular proliferation, survival, migration and differentiation (38). There is also substantial evidence for the importance of FGF signalling in the pathogenesis of diverse tumour types (38). As for the FGF-Rs, quercetin $(2 \mu \mathrm{M})$ also greatly inhibited the activity of PDGF-R- $\alpha$ and $-\beta$ (Fig. 5L). PDGF (plateletderived growth factor) was one of the first polypeptide growth factors identified that signals through a cell surface tyrosine kinase receptor (PDGF-R) to stimulate various cellular functions including growth, proliferation, and differentiation (39). George (39) has reported that since then, several related genes have been identified constituting a family of ligands and their cognate receptors, as illustrated in Fig. 5L. To date, PDGF expression has been shown in a diverse set of tumour types, from glioblastoma to prostate carcinoma (39).

\section{Discussion}

Cancer remains a disease that is devastating because more than $90 \%$ of cancer patients die after tumour metastases due to the intrinsic resistance of metastatic cells to apoptosis, knowing that the majority of the currently available anticancer drugs are unfortunately apoptosis inducers (40-42). Many cancer types also display intrinsic resistance to proapoptotic stimuli even before metastasising, including NSCLC (43-45), melanoma $(46,47)$, pancreatic cancer $(48,49)$, oesophageal cancer $(50)$ and glioma $(51,52)$. Apart from the lack of response to apoptotic drugs, many cancers also develop an acquired chemoresistance during chronic treatments: the multidrug resistance (MDR) phenotype, which is a phenomenon caused by decreased intracellular drug accumulation in the cancer cells due to enhanced drug efflux $(53,54)$.

The partial inhibition of a small number of kinases appears to be a promising strategy to overcome the intrinsic resistance to apoptosis and/or the acquisition of the MDR phenotype by cancer cells $(9,55-57)$. As single compounds, some polyphenols such as curcumin, resveratrol and the green tea polyphenol epigallocatechin-3-gallate (EGCG) have the potential to target multiple kinases that have been implicated in cancer cell biology (58-61). This targeting ability is in addition to the multiple anticancer properties of polyphenols that have already been reported, such as anti-oxidative, proapoptotic, DNA damaging, anti-angiogenic, and immunostimulatory effects (9).

In the current study, the $\mathrm{IC}_{50}$ in vitro growth-inhibitory concentration of quercetin was determined in seven human and one mouse cancer cell lines by means of the MTT colorimetric assay. Of these eight cancer cell lines, we previously demonstrated high levels of resistance to pro-apoptotic stimuli for the human U373 and T98G glioblastoma cells $(50,62)$, the A549 NSCLC $(15,44)$ and the SKMEL-28 melanoma (47). In the same manner, we demonstrated the sensitivity to proapoptotic stimuli of the human MCF-7 breast cancer (63), the PC-3 prostate cancer (63), and the mouse B16F10 melanoma (47) cell lines. We observed no statistically significant $(\mathrm{p}>0.05)$ differences in the $\mathrm{IC}_{50}$ values for quercetin between cancer cell lines that are sensitive or resistant to pro-apoptotic stimuli (Fig. 1).

Quercetin is commonly present as a glycoside and is converted to glucuronide/sulphate conjugates during intestinal absorption. Therefore, only conjugated metabolites are found in circulating blood (6). Although metabolic conversion attenuates its biological effects, active aglycone may be generated from the glucuronide conjugates by enhanced Bglucuronidase activity during inflammation (6).

The fact that quercetin (but not the glycosylated forms of quercetin; see Fig. 1) displays significant anticancer activity in cancer cells that are sensitive to proapoptotic stimuli as well as in cancer cells that display various levels of resistance to such triggers may be due at least in part to the fact that this compound exerts marked antikinase activity. As recently covered by Hou and Kumamoto (27), the inhibition of protein kinases has emerged as an important target for cancer chemoprevention and therapy. Hou and Kumamoto (27) report that accumulated data have shown that flavonoids exert chemopreventive effects by acting not only as conventional hydrogendonating antioxidants but also on protein kinase signalling pathways. Recent studies have shown that flavonoids can bind directly to many protein kinases, including Akt/protein kinase B (Akt/PKB), Fyn, Janus kinase 1 (JAK1), mitogenactivated protein kinase kinase 1 (MEK1), phosphoinositide 3-kinase (PI3K), mitogen-activated protein (MAP) kinase kinase 4 (MKK4), Raf1 and $\zeta$ chain-associated 70-kDa protein (ZAP-70) kinase. The flavonoids then alter the phosphorylation state of the kinases to regulate multiple cell signalling pathways in the carcinogenesis processes (27). The current study found a significant additional number of kinases that are targets for the flavonoid quercetin. The activities of kinases ABL1, Aurora-A, -B, -C, CLK1, FLT3, JAK3, MET, NEK4, NEK9, PAK3, PIM1, RET, FGF-R2, PDGF-R $\alpha$ and $-R ß$ were the most markedly inhibited by quercetin. Indeed, at $2 \mu \mathrm{M}$ quercetin, a concentration that represents $<10 \%$ of its $\mathrm{IC}_{50}$ growth-inhibitory concentration calculated from eight distinct cancer cell lines (see Fig. 1), decreased the activity of the 16 kinases mentioned above by greater than $80 \%$ (see Fig. 5). Many of these kinases are involved in the control of mitotic processes. Indeed, the quantitative videomicroscopy analyses reported in Fig. 2 revealed that quercetin displayed anti-mitotic activity, leading to cell death (Fig. 2). 
Rodent studies have already demonstrated that dietary administration of quercetin prevents chemically-induced carcinogenesis, especially in the colon, whereas epidemiological studies have indicated that an intake of quercetin may be associated with the prevention of lung cancer (6).

In conclusion, the current study found that quercetin exerts its anticancer activity, at least partly, through the inhibition of the activity of a large set of kinases and that this inhibitory activity occurred in vitro at concentrations of about one-tenth of its growth-inhibitory activity. Quercetin may represent an interesting chemical scaffold from which to generate novel derivatives that have a diverse set of antikinase profiles.

\section{Acknowledgements}

R.K. is a Director of Research at the Fonds National de la Recherche Scientifique (FNRS), Belgium. The current study has been carried out thanks to grants awarded by WallonnieBruxelles International (WBI).

\section{References}

1. Newman DJ and Cragg GM: Natural products as sources of new drugs over the last 25 years. J Nat Prod 70: 461-477, 2007.

2. Liu HL, Jiang WB and Xie MX: Flavonoids: Recent advances as anticancer drugs. Recent Patents Anti-Cancer Drug Discov (In press).

3. Deeni YY and Sadiq NM: Antimicrobial properties and phytochemical constituents of the leaves of African mistletoe (Tapinanthus dodoneifolius (DC) Danser) (Loranthaceae): an ethnomedicinal plant of Hausaland, Northern Nigeria. J Ethnopharmacol 83: 235-240, 2002.

4. Ouedraogo M, Carreyre H, Vandenbrouck C, Bescond J, Raymond G, Guissou IP, Cognard C, Becq F, Potreau D, Couson A, Marrot J and Coustard JM: Structure elucidation of a dihydropyranone from Tapinanthus dodoneifolius. J Nat Prod 70: 2006-2009, 2007.

5. Ren W, Qiao Z, Wang H, Zhu L and Zhang L: Flavonoids: Promising anticancer agents. Med Res Rev 23: 519-534, 2003.

6. Murakami A, Ashida H and Terao J: Multitargeted cancer prevention by quercetin. Cancer Lett 269: 315-325, 2008.

7. Jagtap S, Meganathan K, Wagh V, Winkler J, Hescheler J and Sachinidis A: Chemoprotective mechanism of the natural compounds, epigallocatechin-3-O-gallate, quercetin and curcumin against cancer and cardiovascular diseases. Curr Med Chem 16: 1451-1462, 2009.

8. Williams RJ, Spencer JP and Rice-Evans C: Flavonoids: antioxidants or signaling molecules? Free Radic Biol Med 36: $838-849,2004$

9. Lamoral-Theys D, Pottier L, Dufrasne F, Nève J, Dubois J, Kornienko A, Kiss R and Ingrassia L: Natural polyphenols that display anticancer properties through inhibition of kinase activity. Curr Med Chem 17: 812-825, 2010.

10. Gilbert ER and Liu D: Flavonoids influence epigeneticmodifying enzyme activity: Structure-function relationships and the therapeutic potential for cancer. Curr Med Chem 17: $1756-1768,2010$

11. Jeong JH, An JY, Kwon YT, Li LY and Lee YJ: Quercetininduced ubiquitination and down-regulation of Her-2/neu. J Cell Biochem 105: 585-595, 2008

12. Hayot C, Farinelle S, De Decker R, Decaestecker C, Darro F, Kiss $\mathrm{R}$ and Van Damme M: In vitro pharmacological characterizations of the anti-angiogenic and anti-tumor cell migration properties mediated by microtubule-affecting drugs, with special emphasis on the organization of the actin cytoskeleton. Int J Oncol 21: 417-425, 2002.

13. Joseph B, Darro F, Béliard A, Lesur B, Collignon F, Decaestecker C, Frydman A, Guillaumet G and Kiss R: 3-aryl2-quinolone derivatives: synthesis and characterization of in vitro and in vivo anti-tumor effects with emphasis on a new therapeutical target connected with cell migration. J Med Chem 45: 2543-2555, 2002.
14. Lamoral-Theys D, Andolfi A, Van Goietsenoven G, Cimmino A, Le Calvé B, Wauthoz N, Mégalizzi V, Gras T, Bruyère C, Dubois J, Mathieu V, Kornienko A, Kiss R and Evidente A: Lycorine, the main phenanthridine Amaryllidaceae alkaloid, exhibits significant antitumor activity in cancer cells that display resistance to proapoptotic stimuli: An investigation of structureactivity relationship and mechanistic insight. J Med Chem 52: 6244-6256, 2009.

15. Lamoral-Theys D, Pottier L, Kerff F, Dufrasne F, Proutière F, Wauthoz N, Neven P, Ingrassia L, Van Antwerpen P, Lefranc F, Gelbcke M, Pirotte B, Kraus JL, Nève J, Kornienko A, Kiss R and Dubois J: Simple di- and trivanillates exhibit cytostatic properties toward cancer cells resistant to pro-apoptotic stimuli. BioOrg Med Chem 18: 3823-3833, 2010.

16. Mijatovic T, Op De Beeck A, Van Quaquebeke E, Dewelle J, Darro F, de Launoit Y and Kiss R: The cardenolide UNBS1450 is able to deactivate NF-kappaB-mediated cytoprotective effects in human non-small-cell-lung cancer (NSCLC) cells. Mol Cancer Ther 5: 1-9, 2006.

17. Le Mercier M, Lefranc F, Mijatovic T, Debeir O, Haibe-Kains B, Bontempi G, Decaestecker C, Kiss R and Mathieu V: Evidence of galectin-1 involvement in glioma chemoresistance. Toxicol Appl Pharmacol 229: 172-183, 2008.

18. Delbrouck C, Doyen I, Belot N, Decaestecker C, Ghanooni R, de Lavareille A, Kaltner H, Choufani G, Danguy A, Vandenhoven G, Gabius HJ, Hassid S and Kiss R: Galectin-1 is overexpressed in nasal polyps under budesonide and inhibits eosinophil migration. Lab Invest 82: 147-158, 2002.

19. Lefranc F, James S, Camby I, Gaussin JF, Darro F, Brotchi J, Gabius HJ and Kiss R: Combined cimetidine and temozolomide, compared with temozolomide alone: significant increases in survival in nude mice bearing U373 human glioblastoma multiforme orthotopic xenograft. J Neurosurg 102: 706-714, 2005.

20. Mégalizzi V, Mathieu V, Mijatovic T, Gailly P, Debeir O, De Neve N, Van Damme M, Bontempi G, Haibe-Kains B, Decaestecker C, Kondo Y, Kiss R and Lefranc F: 4-IBP: a sigma-1 receptor agonist decreases the migration of human cancer cells including glioblastoma cells in vitro and sensitizes them in vitro and in vivo to the cytotoxic insults of proapoptotic and pro-autophagic drugs. Neoplasia 9: 358-369, 2007.

21. Lefranc F, Mijatovic T, Kondo Y, Sauvage S, Roland I, Krstic D, Vasic V, Gailly P, Kondo S, Blanco G and Kiss R: Targeting the alpha-1 subunit of the sodium pump (the $\mathrm{Na}^{+} / \mathrm{K}^{+}$-ATPase) to combat glioblastoma cells. Neurosurgery 62: 211-222, 2008.

22. Agrawal M, Garg RJ, Kanzarjian H and Cortes J: Chronic myeloid leukemia in the tyrosine kinase inhibitor era: what is the 'best' therapy. Curr Oncol Rep 12: 302-313, 2010.

23. Boss DS, Beijnen JH and Schellens JHM: Clinical experience with Aurora kinase inhibitors: a review. Oncologist 14: 780793, 2009.

24. Garuti L, Roberti M and Bottegoni G: Small molecule aurora kinase inhibitors. Curr Med Chem 16: 1949-1963, 2009.

25. Collis SJ and Boulton SJ: Emerging links between the biological clock and the DNA damage response. Chromosoma 116: 331-339, 2007.

26. Wiernik PH: FLT3 inhibitors for the treatment of acute myeloid leukemia. Clin Adv Hematol Oncol 8: 429-444, 2010.

27. Hou DX and Kumamoto T: Flavonoids ass protein kinase inhibitors for cancer chemoprevention: direct binding and molecular modeling. Antioxid Redox Signal 13: 691-719, 2010.

28. Cornejo NG, Boggon TJ and Mercher T: JAK3: a two-faced player in hematological disorders. Int J Biochem Cell Biol 41: 2376-2379, 2009.

29. Canadas I, Rojo F, Arumi-Uria M, Rouira A, Albanell J and Arriola E: cMET as a new therapeutic target for the development of novel anticancer drugs. Clin Transl Oncol 12: 253-260, 2010.

30. De Carcer G, Perez de Castro I and Malumbres M: Targeting cell cycle kinases for cancer therapy. Curr Med Chem 14: 969-985, 2007.

31. O'Regan L, Blot J and Fry AM: Mitotic regulation by NIMArelated kinases. Cell Div 2: 25, 2007.

32. Molli PR, Li DQ, Murray BW, Rayala SK and Kumar R: PAK signalling in oncogenesis. Oncogene 28: 2545-2555, 2009.

33. Wells CM and Jones GE: The emerging importance of group II PAKs. Biochem J 425: 465-473, 2010.

34. Shah N, Pang B, Yeoh KG, Thorn S, Chen CS, Lilly MB and Salto-Tellez M: Potential roles for the PIM1 kinase in human cancer - a molecular and therapeutic appraisal. Eur J Cancer 44: 2144-2151, 2008. 
35. Amaravadi $\mathrm{R}$ and Thompson $\mathrm{CB}$ : The survival kinases Akt and Pim as potential pharmacological targets. J Clin Invest 115: 2618-2624, 2005.

36. Wells SA Jr and Santoro M: Targeting the RET pathway in thyroid cancer. Clin Cancer Res 15: 7119-7123, 2009.

37. Cook KM and Figg WD: Angiogenesis inhibitors: current strategies and future prospects. CA Cancer J Clin 60: 222-243, 2010.

38. Turner $\mathrm{N}$ and Grose R: Fibroblast growth factor signalling: from development to cancer. Nat Rev Cancer 10: 116-129, 2010.

39. George D: Platelet-derived growth factor receptors: a therapeutic target in solid tumors. Semin Oncol 28: 27-33, 2001.

40. Simpson CD, Anyiwe K and Schimmer AD: Anoikis resistance and tumor metastasis. Cancer Lett 272: 177-185, 2008.

41. Savage P, Stebbing J, Bower M and Crook T: Why does cytotoxic chemotherapy cure only some cancers? Nat Clin Pract Oncol 6: 43-52, 2009.

42. Wilson TR, Johnston PG and Longley DB: Anti-apoptotic mechanisms of drug resistance in cancer. Curr Cancer Drug Targets 9: 307-319, 2009 .

43. Denlinger CE, Rundall BK and Jones DR: Modulation of antiapoptotic cell signaling pathways in non-small cell lung cancer: the role of NF-kappaB. Semin Thorac Cardiovasc Surg 16: 28-39, 2004.

44. Han S and Roman J: Targeting apoptotic signalling pathways in human lung cancer. Curr Cancer Drug Targets (In press).

45. Mathieu A, Remmelink M, D'Haene N, Penant S, Gaussin JF, Van Ginckel R, Darro F, Kiss R and Salmon I: Development of a chemoresistant orthotopic human nonsmall cell lung carcinoma model in nude mice. Cancer 101: 1908-1918, 2004.

46. Soengas MS and Lowe SW: Apoptosis and melanoma resistance. Oncogene 22: 3138-3151, 2003.

47. Mathieu V, Pirker C, Martin de Lassalle E, Vernier M, Mijatovic T, DeNeve N, Gaussin JF, Dehoux M, Lefranc F, Berger W and Kiss R: The sodium pumpa alpha-1 subunit: a disease progression-related target for metastatic melanoma treatment. J Cell Mol Med 13: 3960-3972, 2009.

48. El Maalouf G, Le Tourneau C, Batty GN, Faivre S and Raymond E: Markers involved in resistance to cytotoxics and targeted therapeutics in pancreatic cancer. Cancer Treat Rev 35: $167-174,2009$.

49. Wong HH and Lemoine NR: Pancreatic cancer: molecular pathogenesis and new therapeutic targets. Nat Rev Gastroenterol Hepatol 6: 412-422, 2009.

50. D'Amico TA and Harpole DH Jr: Molecular biology of esophageal cancer. Chest Surg Clin N Am 10: 451-469, 2000.
51. Branle F, Lefranc F, Camby I, Jeuken J, Geurts-Moespot A, Sprenger S, Sweep F, Kiss R and Salmon I: Evaluation of the efficiency of chemotherapy in in vivo orthotopic models of human glioma cells with and without $1 \mathrm{p} / 19 \mathrm{q}$ deletions and in C6 rat orthotopic allografts serving for the evaluation of surgery combined with chemotherapy. Cancer 95: 641-655, 2002.

52. Lefranc F, Brotchi J and Kiss R: Possible future issues in the treatment of glioblastomas, with a special emphasis on cell migration and the resistance of migrating glioblastoma cells to apoptosis. J Clin Oncol 23: 2411-2422, 2005.

53. Anuchapreeda S, Leechanachai P, Smith MM, Ambudkar SV and Limtrakul PN: Modulation of P-glycoprotein expression and function by curcumin in multidrug-resistant human KB cells. Biochem Pharmacol 64: 573-582, 2002.

54. Mayur YC, Peters GJ, Prasad VV, Lemo C and Sathish NK: Design of new drug molecules to be used in reversing multidrug resistance in cancer cells. Curr Cancer Drug Targets 9: 298-306, 2009.

55. Fedorov O, Müller S and Knapp S: The (un)target cancer kinome. Nat Chem Biol 6: 166-169, 2010.

56. Gossage L and Eisen T: Targeting multiple kinase pathways: a change in paradigm. Clin Cancer Res 16: 1973-1978, 2010.

57. Knight ZA, Lin H and Shokat KM: Targeting the cancer kinome through polypharmacology. Nat Rev Cancer 10: 130-137, 2010.

58. Butt MS and Sultan MT: Green tea: nature's defense against malignancies. Crit Rev Food Sci Nutr 49: 463-473, 2009.

59. Kraft TE, Parisotto D, Schempp C and Efferth T: Fighting cancer with red wine? Molecular mechanisms of resveratrol. Crit Rev Food Sci Nutr 49: 782-799, 2009.

60. Liu EH, Qi LW, Wu Q, Peng YB and Li P: Anticancer agents derived from natural products. Mini Rev Med Chem 9: 1547-1555, 2009.

61. Bar-Sela G, Epelbaum R and Schaffer M: Curcumin as an anticancer agent: review of the gap between basic and clinical applications. Curr Med Chem 17: 190-197, 2010.

62. Ingrassia L, Lefranc F, Dewelle J, Pottier L, Mathieu V, SpieglKreinecker S, Sauvage S, El Yazidi M, Dehoux M, Berger W, Van Quaquebeke E and Kiss R: Structure-activity-relationship analysis of novel derivatives of narciclasine (an Amaryllidaceae Isocarbostyril alkaloid) as potential anti-cancer agents. J Med Chem 52: 1100-1114, 2009.

63. Dumont $\mathrm{P}$, Ingrassia L, Rouzeau S, Ribaucour F, Thomas S, Roland I, Darro F, Lefranc F and Kiss R: The Amaryllidaceae isocarbostyril narciclasine induces apoptosis by activation of the Death Receptor and/or the mitochondrial pathways in cancer cells but not in normal fibroblasts. Neoplasia 9: 766-776, 2007. 